\title{
Ge Graphos

\section{DECADENCIA DE LA INFRAESTRUCTURA FERROVIARIA Y EFECTOS EN LA ESTRUCTURA URBANA (SANTA FE, ARGENTINA)}

\author{
Arq. María Alejandra Saus \\ Doctorado en Humanidades y Artes - Mención Historia \\ Universidad Nacional de Rosario (Rosario, Provincia de Santa Fe, Argentina) \\ Correo electrónico: produccioncientificaydocencia@gmail.com
}

Recibido: 2 de junio de 2012. Aceptado: 25 de junio de 2012

\section{RESUMEN}

Abordar al ferrocarril como vector para la modernización y el crecimiento urbano, resulta recurrente en nuestro medio historiográfico. Estos textos asumen a la infraestructura en pleno ciclo de uso, cuando se consideraba un elemento vital para la estructura urbana. Contrariamente, el objetivo de este artículo es caracterizar al universo ferroviario ante un ciclo de uso descendente de la infraestructura. Porque a principios del siglo XX el ferrocarril dejó de representar progreso, para actuar como un sistema anacrónico que entorpecía el desarrollo urbano. El hecho se entronca con la situación periférica de Argentina, subordinada a fluctuaciones económicas que resintieron inversiones foráneas. Asimismo, se acompaña de un discurso crítico, nutrido en el uso del transporte automotor y en las consecuencias de una primera etapa de expansión urbana que había integrado a los rieles. Por ello, el texto describe la situación y explica cómo el dominio ferroviario se volvió impermeable y un obstáculo urbano.

Palabras clave: Infraestructura ferroviaria, efecto barrera, bordes urbanos.

\section{RAILROAD INFRASTRUCTURE DECLINE AND ITS IMPACT ON URBAN STRUCTURE. SANTA FE CITY, ARGENTINA}

\section{ABSTRACT}

An approach to railroad as a vector for modernization and urban growth is a recurrent topic in our historiographic environment. These texts take infrastructure in its full usage cycle, when it was considered a vital element for urban structure. On the other hand, the scope of this article is to characterize the railroad universe facing a usage 
cycle descending from infrastructure, since at the beginning of the 20th Century railroad did not represent progress anymore. It became an anachronistic system hindering urban development. The fact is closely related to Argentina's peripheral situation, subordinated to economic fluctuations that affected foreign investments. Besides, it is accompanied by a critical discourse, nourished by the use of automotive transport and by the consequences of a first stage of urban expansion that had incorporated the rails. For this reason, this text analyzes the situation and explains why the railroad system became impervious and an urban obstacle.

Key words: Railroad Infrastructure, Barreir Effect, Urban Edges.

\section{DECADÊNCIA DA INFRA-ESTRUTURA FERROVIÁRIA E EFEITOS NA ESTRUTURA URBANA SANTA FE, ARGENTINA}

\section{RESUMO}

Abordar a ferrovia como um vetor para a modernização e crescimento urbano, é recorrente na nossa historiografia. Estes textos assumem a infra-estrutura em completo ciclo de uso, enquanto foi considerado essencial para a estrutura urbana. Contrariamente, o objetivo deste trabalho é caracterizar o universo ferroviário como um ciclo descendente da infra-estrutura. Porque ao início do século XX, a ferrovia deixou de representar o progresso, para atuar como um sistema anacrônico que impedia o desenvolvimento urbano. O fato está ligado com a situação periférica da Argentina, sujeitos a flutuações econômicas, as quias ressentiam os investimentos estrangeiros. Também acompanhada por um discurso crítico, alimenta-se no uso do transporte automóvel e nas consequências de uma primeira fase de expansão urbana que tinha integrado os trilhos. Portanto, o texto descreve a situação e explica como o domínio ferroviário tornou-se impermeável e um obstáculo urbano.

Palavras chave: Infra-estrutura ferroviária, efeito barreira, periferia urbana.

\section{INTRODUCCIÓN}

Transcurrido un período de bonanza para la ciudad de Santa Fe, a la disminución de las inversiones ferroviarias producto de la crisis internacional y de la Primera Guerra Mundial y al malestar de las "fuerzas vivas" locales, se sumó la retórica del urbanismo que estaba en vías de consolidación hacia un saber con aspiraciones científicas y que tendría a la infraestructura ferroviaria como vital enemigo. En la construcción de la demanda de esta disciplina en ciernes, para los urbanistas el ferrocarril fue el principal ariete. En ese marco, se construyó el diagnóstico de los problemas del área central de Santa Fe en base a los inconvenientes provocados por los enlaces ferroviarios, al tiempo que éstos fueron herramienta proyectual para segregar a las clases trabajadoras a la periferia. Así fue como los planes urbanos intentaron liberar al mercado de tierras de un obstáculo, para ponerlo en otro lado, donde ese borde fuera funcional a la segregación social. Pero debe decirse que las compañías ferroviarias, al reforzar las medidas de seguridad solicitadas por el Municipio, aislaron a las infraestructuras estableciendo espacios estancos que ya no podían ser tolerados en áreas centrales. Paralelamente, esto conllevó a imposibilitar la expansión productiva del sistema ferroviario por falta de 
espacio, contribuyendo al estancamiento del capital privado. Asimismo, las crónicas de la prensa que representaba a los sectores hegemónicos repudiaron al ferrocarril por esta causa. Veremos a continuación cómo fueron convergiendo estos factores para nutrir un discurso crítico hacia el ferrocarril. Haremos hincapié en los efectos espaciales de incomunicación propiciados por las medidas de seguridad tomadas por las empresas ferroviarias, para comprender que el confinamiento de las infraestructuras contribuyó a que se planteara como solución el traslado de las mismas a la periferia urbana.

\section{CONSTRUCCIÓN DE LA RETÓRICA DEL ANACRONISMO FERROVIARIO}

Hacia la década del '20 una serie de argumentos de diversa índole irían estructurando un discurso de disconformidad hacia las empresas del riel, hasta converger en el diagnóstico de los planes urbanos. En principio, serían las crisis económicas que fueron afectando a las inversiones extranjeras, que volvían al ferrocarril un servicio deficiente, rudimentario, precario, anacrónico. El emblema del progreso del siglo XIX se había tornado el resabio de un glorioso pasado, pero pasado al fin. Sus infraestructuras, ahora encorsetadas en intersticios de trama urbana, estaban atrapadas en una serie de paredones y vallados que garantizaban seguridad frente a posibles accidentes con personas o vehículos, pero que definitivamente clausuraban toda conexión visual o espacial entre el dominio social de la ciudad y el dominio funcional del ferrocarril, que hasta entonces habían sido públicos (Meyer, 1999). Previamente articulados, en el siglo $\mathrm{XX}$ ambos espacios se habían convertido en una pareja que perdía el diálogo y ello no tardaría en plantear que era necesario el divorcio. Trasladar toda esa infraestructura céntrica al espacio periurbano era la estrategia de los urbanistas, pero ello condenaba a las estaciones a desaprovechar la fluencia de potenciales clientes que tenían en áreas concurridas, además de sentenciar que implicaba perder la competencia con el automóvil. Asimismo, las constantes tensiones entre los intereses de la ciudad y los del capital privado ferroviario, harían inviable ese proyecto que privilegiaba el criterio urbanístico (Santos y Ganges, 2007).

\section{Otro ciclo en la historia del ferrocarril ahora decadente}

A diferencia del caso europeo, en las jóvenes naciones de América la construcción de los ferrocarriles se había adelantado a la demanda del sistema de transporte (López, 2009). Se trataba de una infraestructura aliada a un anhelo de expansión y control territorial, que de forma diferida tendría un correlato en la efectiva explotación del sistema de transporte. Por este motivo, aunado a las limitaciones del tesoro nacional que incipientemente estaba apostando al desarrollo económico, era inminente la concurrencia del capital foráneo para dar curso al proyecto ferroviario. Por su parte, Gran Bretaña había terminado el proceso de instalación de la infraestructura en su territorio y disponía de la experiencia y los excedentes necesarios para invertir en el exterior. Como lo había planteado la clase dirigente argentina, se habían otorgado todos los incentivos necesarios para que ese capital se "naturalizara" entre nosotros. El cuadro de dependencia entre el centro y la periferia en esta expansión del capital ferroviario, se deslizó sobre rieles hasta la Primera Guerra Mundial. Hasta ese momento, en Argentina aún resonaban los ecos del Centenario, la algarabía de sus festejos y la bonanza del modelo agroexportador, superada la crisis de 1890. Debido al conflicto bélico que 
afectó a parte de Europa, las inversiones en el extranjero disminuyeron. Sin embargo, en 1918 el fin de la contienda fue restableciendo los lazos del matrimonio transoceánico.

Comenzaron a percibirse los logros de una segunda etapa de industrialización, la que rectificó los avances tecnológicos desde el estallido de la Revolución Industrial, especialmente en la industria química, eléctrica y petrolífera. En ese contexto, despuntó el automóvil como medio de transporte alternativo y se confiaba en su desarrollo masivo. En principio, no saldría de selectos reductos, pero su producción en serie y presentación como variante con demandas infraestructurales más flexibles, lo hicieron acreedor de amplio consenso. El automóvil se fue convirtiendo en un enemigo silencioso para el ferrocarril, su primordial oponente sobre tierra y nuevo ídolo de una modernidad pragmática. Contrariamente, la expansión y modernización ferroviaria en Argentina dependían del capital exógeno, siempre sujeto a recortes en tiempos de inestabilidad. Hasta la Crisis Económica Internacional de 1929 el intercambio con Gran Bretaña era fluido: ingresaban capitales, manufacturas, tecnologías y materiales (sin mediar compromisos aduaneros); salían materias primas y alimentos. La crisis internacional significó poner nuevamente de relieve las desventuras de esa relación asimétrica y alimentó el deseo de intervención estatal en la economía. En ese contexto escribió Scalabrini Ortiz (2006) explicando la operatoria del imperialismo británico y la sumisión del territorio argentino a sus dominios ferroviarios. Así, junto a las franquicias del riel, supuestamente se enajenaban la soberanía nacional y los recursos naturales.

Por su parte "...La red ferroviaria conformada con líneas que competían entre sí y con diferentes trochas, generaba además una serie de instalaciones superfluas especialmente en las grandes ciudades donde cada empresa tenía su propia estación, sus depósitos de locomotoras, sus galpones de carga y sus playas de maniobras entorpeciendo el desarrollo urbano..." (Waddell, 2009, p. 60). El disgusto que se fue instalando en Argentina contra el ferrocarril tuvo así un correlato espacial. Toda esa infraestructura redundante, despojada de inversiones, incompatible con el automóvil y reñida con la expansión urbana; yacía en las ciudades como un obstáculo. En Santa Fe, primero fue la prensa de elite quien denunció esos "atropellos contra los progresos urbanos" y luego un discurso calificado, iría adjetivado el fenómeno. El urbanismo en su proceso de consolidación como saber científico y autónomo sería quien efectuara el diagnóstico y preparara las condiciones para definir lo que hoy denominamos "efecto barrera". Para los españoles fue el "dogal ferroviario", en Argentina se hizo referencia a un "cinturón de cierro". En cualquier caso, una infraestructura en declive y una ciudad en desarrollo, ahora enfrentados. Se fue construyendo así el mito del anacronismo, el que fundó que no era posible ajustar el ferrocarril al espíritu del tiempo, sólo quedaba su paulatino reemplazo por un medio de locomoción moderno. La ciudad ensayaba modalidades para el cambio de paradigma y arbitraba los medios para ocupar los espacios recuperados.

\section{Efecto barrera y bordes al crecimiento urbano}

Ante este estado de cosas, se fue conformando un discurso de términos inéditos. Esos relatos explican y pretenden dar soluciones a un efecto que, aunque paradojal, es

\footnotetext{
1 "EL DERECHO VECINAL Y LA NEGLIGENCIA DE LOS FERROCARRILES". El Litoral, jueves 11 de diciembre de 1930, p. 3.
} 
intrínseco al ferrocarril en las ciudades. Primero, las estaciones ferroviarias estimulan la expansión urbana al dinamizar el mercado de tierras. Una vez consumado este hecho, los tendidos de rieles obstaculizan el siguiente desarrollo, produciendo un descenso en las rentas urbanas (Santos y Ganges, 2007). Otro inconveniente se produce en los cruces a nivel con el automóvil. En rigor, el pasillo ferroviario al generar un canal estanco produce discontinuidad entre "paquetes urbanos" (López Lara, 2005), además de problemas de conectividad, seguridad, anegamiento, etc. Sin embargo, cuando se intenta volver permeable esa barrera, abriendo cruces a nivel, se resuelve la conectividad, pero se incrementan los accidentes de tránsito. Esto exige la colocación de barreras, cabinas para guardabarreras, señalización, pasarelas, etc. Todas estas intervenciones implican gastos para las compañías, que intentarán evadir hasta las últimas consecuencias las exhortaciones municipales. Por otra parte, el intento por liberar el mercado inmobiliario de esos "cinturones de hierro" no fue sencillo de explicitar para los actores del momento, puesto que incluía intereses sectoriales y agentes interesados en promover sus tierras. Por ello, las tintas se cargaron sobre el efecto en el tránsito que parecía acorde con beneficios colectivos. Muy tempranamente se habló de los bloqueos al tránsito vehicular, en tiempos en que la ciudad no era densa, ni estaba tan poblada de vehículos.

Para López Lara (2005) esa expansión especulativa del trazado y tejido urbanos, basada en la nueva centralidad ferroviaria y en ausencia de planificación pública; condujo a que se quite la atención puesta en la arquitectura de la estación como hito, para reflexionar sobre el carácter de límite físico, a menudo funcional y social, que propician los trazados viarios. Como resultado de este proceso, "El 'efecto barrera' dará lugar a dos fenómenos urbanísticos con distintas consecuencias. Las líneas ferroviarias supondrán un límite al crecimiento urbano: de un lado, cuando la ciudad en su crecimiento 'alcanza' el ferrocarril sin sobrepasarlo, éste se convierte más que en una barrera en un borde al crecimiento urbano; de otro lado, cuando la ciudad 'sobrepasa' el ferrocarril, éste se erige en una barrera urbana propiamente dicha y suele generar problemas de funcionalidad y de seguridad vial..." (López Lara, 2005, p. 16). Sin embargo, esta clasificación resulta esquemática para el caso de Santa Fe donde distinguimos tres alternativas de expansión urbana en relación al ferrocarril. Un crecimiento planificado, cruzando las vías (barrio Candioti), donde la infraestructura ferroviaria nunca fue un borde, más bien una barrera que el propio proyecto de urbanización consolidó como tal. Urbanizaciones a norte y sur de las vías, produciendo el "salto" de las mismas, que quedan un tiempo despojadas de trama urbana, hasta completar las tierras intermedias. Por último, polígonos de nueva trama que se trazaron completos con indiferencia hacia el camino del riel que los atravesaba en diagonal. Sólo en los sectores ribereños el terraplén de las vías se constituyó por un tiempo en borde al crecimiento, debido a la sensación de seguridad que éste confería frente al avance de las aguas. En los demás casos, la urbanización se había expandido o generado a "saltos" ignorando las vías, poniendo de manifiesto que en ese proceso de urbanización la geometría de la propiedad de la tierra tuvo más relevancia que la presencia del ferrocarril. ${ }^{2}$

\footnotetext{
2 "Plano Topográfico del Territorio Municipal de Santa Fe. Construido por la Oficina de Ingeniería durante la Administración del Intendente Ingeniero J.A. Doncel, Santa Fe abril de 1895". Dirección Provincial de Catastro.
} 
Figura 1. Plano de 1905. Bordes y Barreras. El enlace semicircular envuelve al "Nuevo Pueblo Candioti"

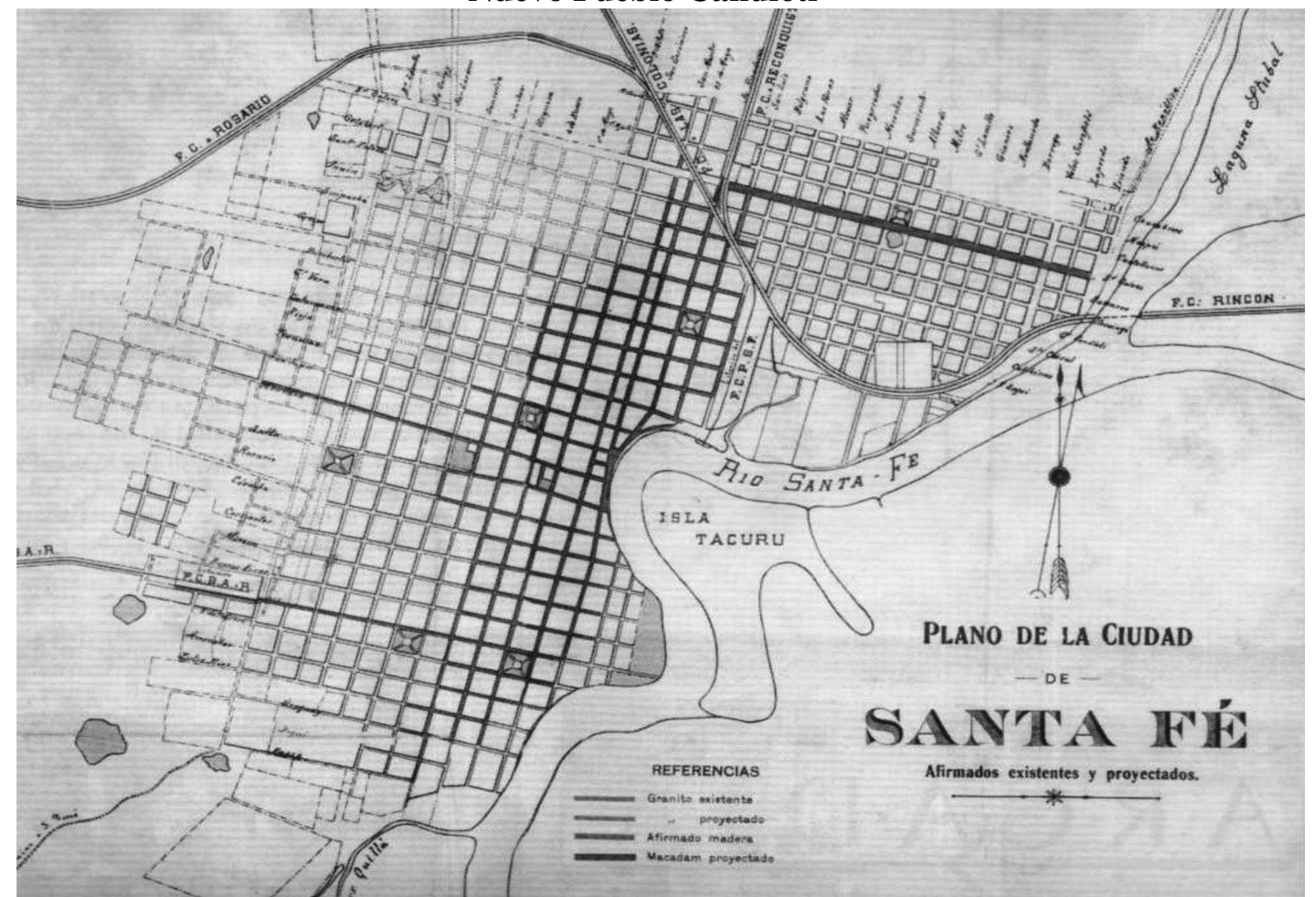

Fuente: "Santa Fe en Planos". Suplemento cartográfico del diario El Litoral. Santa Fe, septiembre/octubre de 2006.

En este sentido debe notarse que las lógicas urbanas primaron sobre las ferroviarias. En esa instancia los tendidos de rieles no estaban determinando los confines de la urbanización, a la manera de una "mancha de aceite" que se expande y se topa con las vías. La presencia del predio de reparaciones Santa Fe Cambios, localizado al norte de la trama urbana, se encontraba ejerciendo atracción para la urbanización, produciendo un "salto" en la continuidad del crecimiento con respecto a la trama del sur. En su mayoría, la población era de obreros ferroviarios que trabajaban en ese polo industrial, pero también de empleados del centro que se habían visto obligados a buscar terrenos más baratos al norte para residir, luego de que la instalación ferroviaria elevara las rentas de la ciudad preexistente. ${ }^{3}$ Por lo visto, casi no podemos hablar de bordes al crecimiento urbano, porque el criterio urbanístico hizo primar el beneficio que representaba para los particulares ofrecer sus tierras a la urbanización de forma aislada y según intereses individuales. Por ello, desde el punto de vista de la morfología urbana no es posible afirmar que los trazados ferroviarios contuvieran por un tiempo el crecimiento, generando un borde físico, aunque sí debemos reconocer que la presencia ferroviaria propició la oportunidad para el negocio inmobiliario. En este sentido, el sector privado construyó la ciudad y luego el Municipio debió ocuparse de proveer los servicios y la infraestructura, dificultados, además, por la discontinuidad espacial de esos sectores con el área central.

\footnotetext{
3 "Plano Topográfico del Territorio Municipal de Santa Fe. Construido por la Oficina de Ingeniería durante la Administración del Intendente Ingeniero J.A. Doncel, Santa Fe abril de 1895". Dirección Provincial de Catastro.
} 
Figura 2. Plano de 1912 y localización de las estaciones, enlaces y urbanizaciones (Amarillo: 1-FCSF 2-FCCA 3-FCCNA. Anaranjado: predio Santa Fe Cambios)

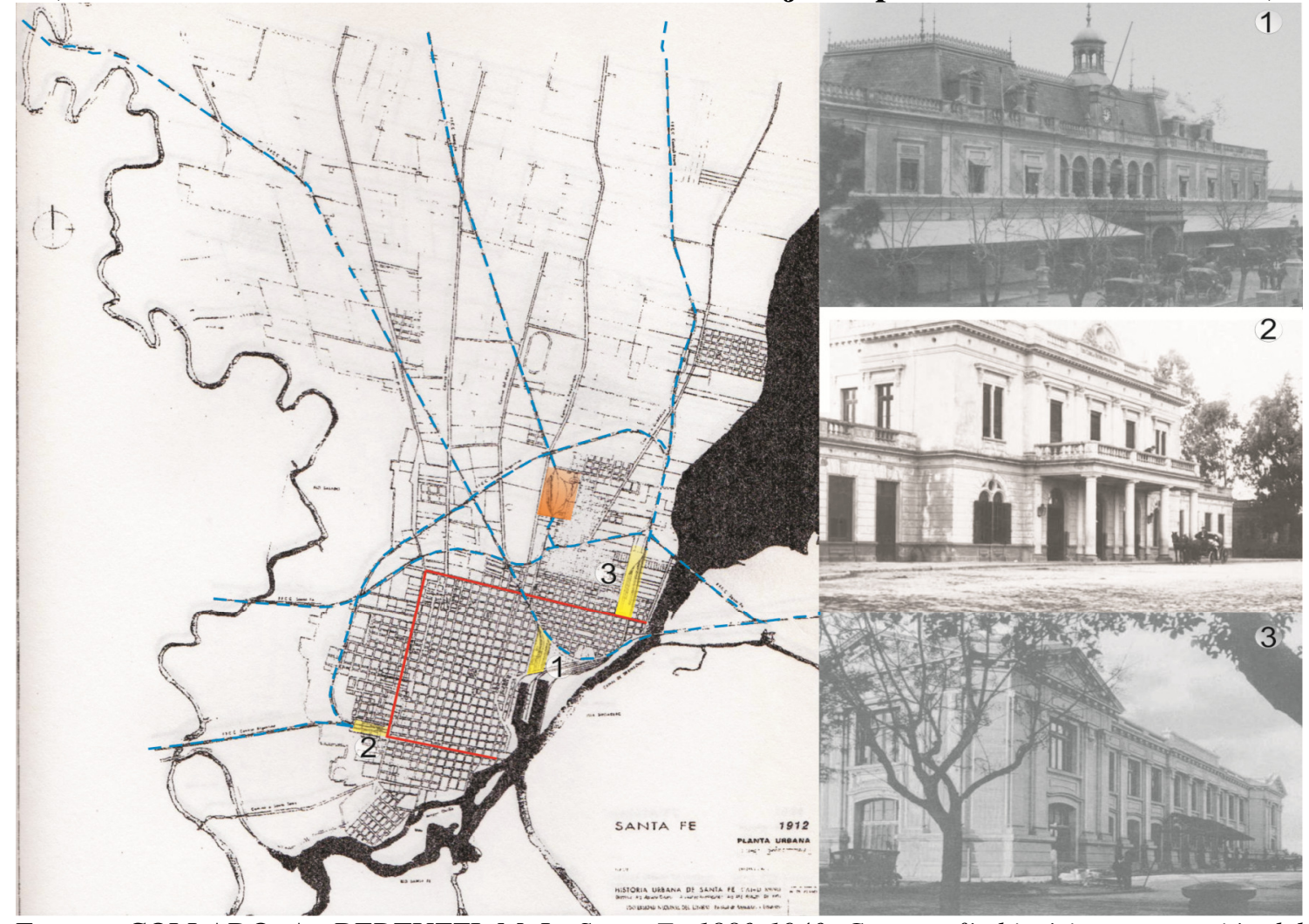

Fuentes: COLLADO, A.; BERTUZZI, M. L. Santa Fe 1880-1940. Cartografía histórica y expansión del trazado. Documento de trabajo $\mathrm{N}^{\circ}$ 4. Santa Fe: Universidad Nacional del Litoral, 1995. // SISTEMA PROVINCIAL DE ARCHIVOS FOTOGRÁFICOS: <www.fotografico.ceride.gov>. Elaboración propia.

\section{Corredores estancos, seguridad vial y reforzamiento de la discontinuidad}

Para las representaciones de la prensa escrita que canalizaba los ideales de los grupos de poder, la conflictividad urbana que establecía ese dominio técnico estaba directamente relacionada con las áreas valiosas que comprometía. ${ }^{4}$ El núcleo central, ${ }^{5}$ el casco histórico ${ }^{6}$ y el bulevar Gálvez; ${ }^{7}$ eran los principales destinatarios de esos reclamos ferroviarios, aún a pesar que hemos demostrado que por el norte de la ciudad existía una gran vitalidad descuidada. ${ }^{8}$ En este sentido y como lo afirma Ponte (1999), la prensa actuó de manera paternalista, creyendo poder apadrinar los reclamos por mejoras urbanísticas. Lo que ocurre, es que desde las crónicas de los sectores privilegiados puede leerse entre lías la situación de los grupos populares. Cuando el periodismo escribe sus loas a las asociaciones vecinales en procura de progresos para los barrios del

\footnotetext{
4 "LOS FF.CC. CONTRA LA COMUNA". Diario El Orden. Martes 26 de noviembre de 1929, p. 3.

5 "¡UNA CIUDAD PARTIDA EN DOS!. Para Abrir Cauce Al Progreso De Santa Fe Es Necesario Aventar Lejos Esta Estación.” El Orden, miércoles 18 de enero de 1933, p. 1.

6 "El F.C. Central argentino está en el deber de construir una nueva estación en Santa Fe. La indiferencia de la empresa respecto del progreso de la ciudad ofende al sentimiento local. LÍNEA EN CONSTANTE AUMENTO ECONÓMICO". El Litoral, viernes 22 de enero de 1937, p. 3.

7 "EL F.C.C.N. CONTRA LA CIUDAD". Diario El Orden, viernes 18 de octubre de 1929, p. 2.

"“LA COMPAÑÍA DEL FERROCARRIL SANTA FE PESE A LA SOLICITACIÓN DE LA COMUNA SIGUE SUS MANIOBRAS EN LOS PASOS A NIVEL EXISTENTES”. El Orden, martes 20 de enero de 1931, p. 5 .
} 
norte, allí debe interpretarse que el gobierno local se encuentra ausente, o que evade sus compromisos públicos, y por eso la necesidad de fraternidad. ${ }^{9}$ La conectividad entre infraestructura y estructura urbana no es un problema del área central, se trata de una dificultad de la ciudad como sistema integral, aunque la prensa sectorice su interés. Las posibilidades de conexión entre barrio Candioti y las vecinales del norte estaban comprometidas. Sin embargo, esas notas ocupaban menos páginas en los diarios que las que hacían referencia a la conectividad entre Candioti y el centro. Volviendo a Ponte, esa es la plusvalía que detenta el documento periodístico, porque de él emanan los hechos y los juicios de valor emitidos sobre ellos. Vayamos ahora a los hechos, para comprender de forma más abstracta las implicancias de esos efectos de discontinuidad.

Entender que el pasillo ferroviario determina la existencia de un corredor estanco, implica la comprensión de varios factores. En principio, los presupuestos de este artículo se fundan en el trabajo acerca del ferrocarril interurbano, es decir, aquel que tiene cabecera o paso por las ciudades pero no atiende a las necesidades del transporte urbano, no sirve, ni asiste a los flujos de tráfico de carácter local, como sí lo hacían los tranvías en el caso de Santa Fe y otras ciudades semejantes. Las estaciones son sólo núcleos de transbordo de pasajeros, de ruptura de cargas, de armado y desarme de formaciones de trenes. Estos procedimientos se repiten recién en la próxima estación o apeadero y entre ellos media sólo un enlace continuo. Santos y Ganges (2007) define a los enlaces como ramales de unión entre estaciones y líneas férreas en las ciudades, especialmente en aquellas en que los ferrocarriles inician o culminan su recorrido. Por enlace se entiende al conjunto de estaciones y ramales, que se distinguen en tres tipos. El caso del enlace de estaciones de cabecera es singular porque requiere el retroceso de la marcha del tren para salir de la estación; otro tipo de unión es la que otorga prioridad a la continuidad del recorrido y demanda que al menos una de las estaciones sea pasante; el tercero es el enlace que no sólo une estaciones, sino también playas de maniobras, talleres, estaciones de intercambio, puertos, etc.

Toda esa infraestructura no es urbana pero se encuentra en las ciudades, aunque inicialmente los rieles son tendidos sobre territorio no urbanizado, determinando sólo una marca o huella sobre el mismo. Cuando la ciudad expande la urbanización (con diversas modalidades y en distintos tiempos) el tejido edilicio se materializa a ambos lados del enlace, delimitando un canal abierto al ferrocarril, pero cerrado a la ciudad, ya que por cuestiones de seguridad las compañías levantarían tapiales, cercos, o alambrados en el trayecto del tren por los núcleos poblados. Sólo en algunos puntos se habilitarían cruces a nivel, entre el ferrocarril y otros modos de transporte, y también por razones de seguridad se dispondrían barreras y dispositivos de señalización, e incluso cabines de guardabarreras. En cualquier caso, cuanto más se multipliquen estos enlaces y sus estaciones en una ciudad, mayor cantidad de pequeños paquetes o islas urbanas quedan "atrapadas" entre los rieles. Las conexiones entre ellas no pueden ser fluidas porque sólo existen algunos sitios habilitados al paso, embudos puntuales por donde se canaliza el tráfico. La impronta geomorfológica de estas marcas lineales es tan indeleble que condiciona irreversiblemente el uso del suelo y, aunque el paso del ferrocarril fuera eliminado, sólo en zonas precisas podría completarse el tejido edilicio

\footnotetext{
${ }^{9}$ LA LABOR PROGRESISTA DE LAS SOCIEDADES VECINALES". El Litoral, miércoles 31 de diciembre de 1941, p. 25.
} 
en tales trazados. Por ello, numerosas veces, ante la desafectación ferroviaria, se proponen nuevas redes de circulación en esos mismos corredores. Las estaciones y playas de maniobras también producen efectos de incomunicación semejantes y pueden diferir la continuidad de la expansión urbana por un determinado tiempo. Cuando el efecto se une a otros factores urbanísticos, como la cercanía al centro, la calidad paisajística, o la degradación ambiental; esa reserva de tierra en suspenso puede convertirse posteriormente en un barrio calificado o marginal.

En 1885 se trazó en Santa Fe un primer enlace del Ferrocarril Santa Fe a las Colonias FCSF $^{10}$ hacia la localidad de Esperanza, con rumbo a las colonias agrícolas del noroeste provincial. Sobre ese vínculo, a la altura de lo que actualmente es el barrio Las Flores (noroeste de la planta urbana) se construyó la estación de paso homónima, que justamente dio origen al distrito. En el año 1886 se materializó la conexión de esta compañía hacia el este, con el puerto de la localidad de Colastiné, estación fluvial que la misma empresa administraba. En un plano de 1907 se verifica que este mismo ramal había sido trasladado hacia el norte, alcanzando su punto máximo para salir al este hacia la laguna Setúbal a la altura de calle Quintana ${ }^{11}$ (Figura 2). El ramal a Reconquista, también del FCSF, tenía su primera parada en la localidad de Recreo y enlazaba todos los poblados que actualmente une la Ruta Nacional $N^{\circ} 11$, hacia el norte provincial. Las vías a Rosario del mismo ferrocarril, partían de la estación de Santa Fe hacia el oeste formando un hemiciclo sobre la cuadrícula. El Ferrocarril Buenos Aires y Rosario FCBAyR ${ }^{12}$ poseía un ramal que partiendo de la ciudad hacia el sur tenía una primer estación pasante en Santo Tomé, cruzando el río Salado. En el año 1911 se trazó el enlace entre la estación y el puerto de Santa Fe, formando un trazado elíptico y terraplenado por el norte de la planta urbana de entonces. Por su parte, el Ferrocarril Central Norte Argentino FCCNA ${ }^{13}$ arribó a la ciudad en 1908 con un enlace hacia el norte del territorio nacional y países limítrofes. El edificio de calle Avellaneda, Dorrego, Javier de La Rosa y Pje. Koch se usaba como estación intermedia entre Santa Fe y Laguna Paiva y de denominó estación Guadalupe. Su construcción comenzó en 1906 y terminó dos años después (Andreis, 2003).

\footnotetext{
${ }^{10}$ Ferrocarril Santa Fe a las Colonias: ferrocarril provincial inaugurado en 1885 y que en 1889 el gobierno arrendara a la compañía francesa Fives Lille. Posteriormente, la empresa transfirió el contrato a la Compañía Francesa de Ferrocarriles de Santa Fe. En este período convenimos en llamarlo Ferrocarril Santa Fe (FCSF). En 1896 el gobierno otorgó en propiedad todas las líneas a la compañía gala, hasta ser absorbido por el Ferrocarril Nacional General Manuel Belgrano (FCNGMB) debido a la nacionalización de los ferrocarriles franceses en 1947. Estaba ubicado al este de la planta urbana, sobre las actuales calles Hipólito Yrigoyen y Belgrano.

${ }^{11}$ MARTÍNEZ, Tomás. 1908. Censo Municipal de Santa Fe. Población, edificación, comercio e industria, 1907. Santa Fe: Imprenta La Argentina.

${ }^{12}$ Ferrocarril Buenos Aires y Rosario: ferrocarril que inauguró su estación en el sector suroeste de la ciudad de Santa Fe en 1891 (FCBAyR). Pertenecía a capitales británicos y se fusionó en 1902 con el Ferrocarril Central Argentino (FCCA), también británico. Fue nacionalizado en 1948 con el nombre de Ferrocarril Nacional General Bartolomé Mitre (FCNGBM) y su edificio aún se encuentra en Gral. López y Dr. Zavalla.

${ }^{13}$ Ferrocarril Central Norte Argentino: (FCCNA, Ferrocarriles del Estado): esta línea pertenecía a los ferrocarriles de fomento del Estado nacional y data en la ciudad desde 1908. Su estación definitiva se proyectó y construyó sobre Bv. Gálvez y calle Avellaneda, entre 1912 y 1928. Luego del proceso de nacionalización recibió el nombre de Ferrocarril Nacional General Manuel Belgrano (FCNGMB) y absorbió al FCSF, cuya estación fue demolida en 1962.
} 
Hacia 1911 se completó el delineado de esos enlaces en la ciudad de Santa Fe. Estos canales aún persisten abiertos en la trama urbana que fue completando los intersticios entre ellos. En algunas discretas excepciones reemplazaron su función primaria: un corto tramo de las vías a Esperanza del FCSF, entre las calles Suipacha y Mariano Comas del área central, que se completó con tejido edilicio; el primer tendido a Colastiné de 1886 que se utiliza para el tráfico rodado, denominado Callejón Caseros y calle Rosalía de Castro, hasta su salida a la Avenida Leandro N. Alem, hacia el sureste; un segmento del segundo ramal a Colastiné que fue convertido en el paseo Intendente Muttis, a partir de calle Vélez Sarsfield hacia el este y a la altura de Quintana; ciclo vías asfaltadas siguiendo el recorrido de las vías férreas; aperturas puntuales y contingentes del terraplén del FCBAyR. El panorama actual aún conserva esa impronta de canales, que en principio fueron sendas sobre el territorio, pero que al expandirse el trazado y el tejido quedaron como corredores con sus bordes materializados. Esa es la lógica del enlace, la que explicamos desde el punto de vista ferroviario pero también urbanístico. Si bien abordamos estas cuestiones desde una perspectiva disciplinar que atiende al espacio urbano, es preciso aclarar que la estrechez del dominio técnico también perjudica al ferrocarril (Santos y Ganges, 2007). En rigor, constriñe sus posibilidades de ampliación, limita su afán económico expansivo y congela sus expectativas de crecimiento e interés inversor. Esto es lo que en el siglo XX los agentes de la ciudad le achacan a las compañías como actitud egoísta, o desinteresada hacia los progresos urbanos; cuando, en realidad, el progreso del ferrocarril ha llegado a su límite, entre otras cosas, por falta de espacio para aumentar maniobras y convoyes.

Pensemos ahora en las responsabilidades de la ciudad ante este estado de cosas que alteran la conectividad urbana y producen segregación espacial. En este sentido, Santos y Ganges afirma que: "Los viales ferroviarios, como infraestructuras lineales que son, con carácter impermeable a la circulación transversal, fragmentan el espacio urbano y pueden producir o inducir a la segregación: estamos ante el efecto barrera de las vías del tren. La falta de medios y de visión a largo plazo provoca la frecuencia de los pasos inferiores angostos, oscuros y hasta sucios y peligrosos, así como los pasos a nivel en plena ciudad, incómodos y que entrañan peligro. El efecto barrera existe como tal por el sólo hecho de existir la línea férrea, pero presenta a menudo una fuerte incidencia debido fundamentalmente a la falta de previsión de las autoridades locales y a un urbanismo inadecuado, que, bien han permitido la creación densa y desordenada de ciudad, bien han obviado sus responsabilidades en materia de infraestructura urbana, no facilitando la permeabilidad a través de la traza férrea y convirtiéndola en una auténtica frontera. Además, aún más grave es que en muchas ocasiones no haya viario longitudinal al trazado férreo, o que sea muy estrecho, o que las tramas urbanas a uno y otro lado de las vías no converjan sobre el plano, es decir, que la continuidad en los trazados transversales sea inviable" (Santos y Ganges, 2007, p. 26). Aún asumiendo esta realidad, para el siglo XIX debemos matizar la responsabilidad del Municipio de Santa Fe, que poco margen de maniobra tenía frente a la gestión ferroviaria nacional, que veía en la instalación del riel el disparador de un ansiado progreso y que no disponía de los saberes que el urbanismo codificaría y sistematizaría más tarde, conjuntamente con su consolidación como saber autónomo. 


\section{Canales y recintos impenetrables construyen el discurso segregativo}

Tres compañías pertenecientes a dominios distintos y un Municipio ávido por incorporar ferrocarriles, parecen ser la clave de una instalación ferroviaria extensiva. Aún no se avizoraba, o resultaba poco factible, suponer un uso compartido de la infraestructura. Ante los paradigmas actuales es sencillo argüir que el Municipio pudo haber sido menos obsecuente con las compañías ferroviarias y que debió mediar algún tipo de planeamiento urbanístico para coordinar criterios urbanos y ferroviarios. Sin embargo, cuando se analiza toda esa infraestructura urbana y se la sitúa en el ruido de las representaciones progresistas del siglo XIX, no era tan fácil suponer cuáles serían los efectos no deseados de esta transformación. Con el paso del tiempo, ferrocarril y ciudad integrarían dominios incompatibles, porque, además, el primero inició un proceso decadente que impide aliarlo a un discurso moderno. Las infraestructuras asistían a un ciclo de paulatina obsolescencia, porque las compañías ferroviarias irían recortando inversiones. Meyer (1999) sostiene que el urbanismo ensayó la segregación espacial entre ambos dominios. Lo que se quebraba en ese episodio era la posibilidad de articulación que resultaba verificable en el siglo XIX, e inicios del XX. Decimos que se inicia una etapa diferente, o un nuevo ciclo. Pero antes que la disciplina manifestara esta intensión proyectual radicalizada de mudar la infraestructura a la periferia urbana, las ciudades habían sido objeto de las medidas de seguridad que señalamos antes. Grindlay Moreno explica aquella antesala argumentando que los espacios del ferrocarril y de la ciudad se volvieron impermeables: "Las infraestructuras se convierten en recintos estancos, ajenos a la vida urbana, sistemas independientes, como enormes barreras para la población que se ha acumulado a su alrededor" (Grindlay Moreno, 2001, p. 130). Por este motivo, explica Meyer que el urbanismo disoció el "dominio público socializado" del "dominio público tecnocrático", estableciendo la segregación espacial entre estructura urbana e infraestructura.

Por otra parte, Grindlay Moreno refiere a una "etapa de acercamiento y crecimiento", que incluye tanto al crecimiento y densificación urbanos, como a la expansión ferroviaria. Porque si al momento de la instalación de los ferrocarriles las estaciones eran precarias y los ramales mínimos, entre 1880 y 1910 se dio en Argentina lo que Tartarini (2005) denomina el "expansionismo ferroviario". En ese momento, se ampliaron o reemplazaron las estaciones provisorias y se multiplicaron kilómetros de ramales, hasta llegar entre 1910 y 1930 al "apogeo y crisis", período en que se construyeron o reformaron estaciones monumentales como la Terminal Retiro del Ferrocarril Central Argentino y la Terminal Constitución del Ferrocarril Sud, en la Capital Federal. La expansión ferroviaria no se detuvo entre 1880 y 1910, ni tampoco la expansión urbana de Santa Fe que pasó de 25.924 habitantes en 1901, ${ }^{14}$ a 44.257 almas en 1907. ${ }^{15}$ Grindlay Moreno conceptualiza el fenómeno de crecimiento urbano diciendo: "La dinámica urbana, que probablemente reconocerá favorablemente en la estrenada infraestructura sus connotaciones positivas (motor del desarrollo, signo de modernidad, etc.), así como el propio carácter urbano de sus construcciones asociadas, se va a aproximar a ésta en su crecimiento ('ensanche') o renovación" (Grindlay Moreno, 2001, p. 129). "Este acercamiento será, desde el punto de vista de la infraestructura, a menudo excesivo e intensivo, ya que supondrá también una importante

\footnotetext{
14 “Ciudad de Santa Fe. Año 1901”. Plano del Censo Municipal de 1901. Fotografía del Departamento de Estudios Etnográficos y Coloniales.

15 "Censo 1907. La Población por Seccional, según nacionalidad". Anuarios Estadísticos Municipales.
} 
limitación en sus posibilidades de expansión y desarrollo. Ambos elementos, infraestructura y ciudad, experimentan un crecimiento que, llegado a su frontera común, presentará una limitación importante por el efecto barrera que entre ellos se crea". (Grindlay Moreno, 2001, p. 130)

A medida que se incrementaba la población urbana de Santa Fe, se dilataba la edificación y se intensificaban los flujos circulatorios; debieron reforzarse las medidas de seguridad. A los murallones que acompañaban a la estación del FCSF, las verjas y pilares del FCCNA sobre calle Vélez Sarsfield, los pasos a nivel y cabines en la intersección de Avenida Rivadavia y Obispo Gelabert y las maniobras realizadas sobre el Bv. Gálvez a la altura del molino harinero Franchino-Lupotti; ${ }^{16}$ se sumaban toda una serie de cruces conflictivos en dirección norte, hacia donde la ciudad se estaba esparciendo. Asimismo, se acrecentó la actividad ferroviaria, tanto en cantidad de pasajeros, mercancías, circulación de formaciones, como de tareas de mantenimiento. Las medidas de seguridad convertidas ahora en verdaderos bordes físicos y límites visuales, inhibieron cualquier tipo de diálogo entre el dominio técnico de la infraestructura y el social de la ciudad. En consecuencia, es posible hacer el siguiente razonamiento: si el ferrocarril ya no podía participar del espacio social y, paralelamente, utilizaba sitios que resultaban valiosos en la estructura urbana ¿por qué no desplazar esos canales y recintos estancos hacia la periferia urbana y ganar terrenos céntricos para la ciudad? Sobre este discurso segregativo cimentó sus propuestas ferroviarias el urbanismo. Si bien el asunto de la conectividad parecía suficiente argumento para la actuación del profesional en procura de beneficios colectivos, también habría intereses sectoriales más solapados como los del técnico para construir la demanda de su intervención, o los particulares interesados en dar una segunda inyección de vitalidad al mercado de la tierra.

El diagnóstico de los urbanistas demuestra que la evolución de la ciudad se encontraba coartada, porque una enmarañada red ferroviaria impedía su desarrollo: “...esa intrincada ramazón que es la red ferroviaria, extendida allí como una tela de araña perniciosa y fatal, impide la vinculación como no sea por unos cuantos pasos a nivel cuyas barreras se cierran con excesiva frecuencia, obstaculizando el libre tránsito y originando nudos de funestas derivaciones". ${ }^{17} \mathrm{Al}$ proponer una estación única en la periferia, el urbanista segregó espacialmente a la infraestructura y liberó a la ciudad de de su trampa. Las trazas ferroviarias eran suplantadas por avenidas de circunvalación y las vías existentes desviadas de la planta urbana para que no impidieran su evolución. Esto es lo que Miguel C. Roca llamaba “...una rápida cirugía de salvación funcional”. ${ }^{18}$ Así, el urbanismo disoció el dominio público socializado del dominio público funcional, segregando estructura urbana e infraestructura ferroviaria. En Santa Fe esto quedaría planeado sólo en las memorias de los planes, pero no sería posible resolver la cuestión de los pasillos estancos en la trama urbana.

\footnotetext{
16 "LA COMPAÑÍA DEL FERROCARRIL SANTA FE PESE A LA SOLICITACIÓN DE LA COMUNA SIGUE SUS MANIOBRAS EN LOS PASOS A NIVEL EXISTENTES". Diario El Orden, martes 20 de enero de 1931, p. 5.

${ }^{17}$ ROCA, Miguel C. 1947. Plan Regulador de la Ciudad de Santa Fe. Buenos Aires: Instituto Argentino de Urbanismo., p. 97.

${ }^{18}$ ROCA, Miguel C. 1947. Plan Regulador de la Ciudad de Santa Fe. Buenos Aires: Instituto Argentino de Urbanismo, p. 95.
} 


\section{CONCLUSIÓN}

En las primeras décadas del siglo XX el contexto histórico empezaría a ser desfavorable para las inversiones ferroviarias. Simultáneamente, su infraestructura quedaría integrada a la estructura urbana y sus enlaces generarían pasillos impermeables. Las necesarias medidas de seguridad reforzarían ese proceso de aislamiento recíproco entre ferrocarril y ciudad, hasta condesar en los planes urbanos que sentenciarían el traslado de la infraestructura al espacio periurbano. La empresa no sería fácil ya que las compañías resistirían el traslado y, en muchas ciudades como Santa Fe, los canales quedarían como cicatrices en la cuadrícula, aún a más de veinte años de las desafectaciones ferroviarias.

\section{BIBLIOGRAFÍA}

ANDREIS, Alejandro Andrés. El ferrocarril. Lo que el tiempo no borró. Santa Fe: Secretaría de Extensión, UNL, 2003.

GRINDLAY MORENO, Alejandro. Los puertos mediterráneos andaluces: centralidad urbana y dimensión territorial. Granada: Universidad de Granada. Departamento de Expresión Gráfica, Arquitectónica y en la Ingeniería, 2001, 683 p.

LÓPEZ LARA, Enrique. Urbanismo y Ferrocarril. PH Boletín del Instituto Andaluz del Patrimonio Histórico. [En línea]. Organización de Estados Iberoamericanos, octubre de 2005, año 13, no 55. <http://www.oei.es >. [15 de enero de 2012]. 15-22 pp.

LOPEZ, Mario J. "Las compañías ferroviarias privadas y el Estado (1857-1984). La llegada del tren: el progreso sobre ruedas”. En: LUNA, Félix. Esplendor y ocaso de los ferrocarriles. Revista Todo es Historia, n 509, 2009, pp. 6-28. 82.

MEYER, Han. City and Port. Transformation of Port Cities. London, Barcelona, New York, Rotterdam. Rotterdam: International Books, 1999, 432 p.

PONTE, Jorge. La fragilidad de la memoria. Mendoza: CRICYT, 1999, 452 p.

SANTO y GANGES, Luis. Urbanismo y ferrocarril. La construcción del espacio ferroviario en las ciudades medias españolas. Madrid: Fundación de los Ferrocarriles Españoles, 2007, 361 p.

SCALABRINI ORTIZ, Raúl. Historia de los Ferrocarriles Argentinos. Buenos Aires: Lancelot, 2006, 406 p.

TARTARINI, Jorge D. Arquitectura Ferroviaria. Buenos Aires: Ediciones Colihue, 2005, 285 p.

WADDELL, Jorge. E. "De la nacionalización a la privatización de Menem. Ferrocarriles argentinos: 60 años de decadencia. En: LUNA, Félix. Esplendor y ocaso de los ferrocarriles. Revista Todo es Historia, no 509, 2009, pp. 58-77. 82. 
(C) Copyright María Alejandra Saus, 2012.

(C) Copyright GeoGraphos. Revista Digital para Estudiantes de Geografía y Ciencias Sociales, 2012.

\section{Ge Graphos}

REVISTA DIGITAL ISSN: $2173-1276$

PARA ESTUDIANTES DE GEOGRAFÍA Y CIENCIAS SOCIALES 